\title{
Evaluating Relative Accommodations in General Binocular Dysfunctions
}

\author{
ÁNGEL GARCÍA, DOO, PILAR CACHO, DOO, and FRANCISCO LARA, DOO \\ Departamento Interuniversitario de Óptica, Universidad de Alicante, Spain (AG, PC), Departamento de Oftalmología, AP y ORL, \\ Universidad de Murcia, Spain (FL)
}

\begin{abstract}
Purpose. To examine the relationship between relative accommodation and general binocular disorders and to establish their importance in the diagnosis of these anomalies. Methods. We analyzed data of negative relative accommodation (NRA) and positive relative accommodation (PRA) in 69 patients with nonstrabismic binocular anomalies. Results. Statistical analysis showed that low values of NRA and PRA were not associated with any particular disorder. High values of PRA ( $\geq 3.50 \mathrm{D})$ were related to the disorders associated with accommodative excess, whereas high values of NRA ( $\geq 2.50 \mathrm{D}$ ) were not related to accommodative excess. Statistical differences suggested that a high value of PRA could distinguish between anomalies. Sensitivity analysis revealed that high PRA was the most sensitive sign in patients with convergence insufficiency combined with accommodative excess $(0.89)$ and one of the most sensitive signs for subjects with accommodative excess $(0.72)$ and for those with convergence excess combined with accommodative excess (0.70). Conclusions. Anomalous results of NRA were not clearly associated with any dysfunction. High values of PRA were related to disorders associated with accommodative excess, so the sign of a high value of PRA should be considered as one of the diagnostic signs of these anomalies. (Optom Vis Sci 2002;79:779-787)
\end{abstract}

Key Words: negative relative accommodation, positive relative accommodation, general binocular dysfunctions

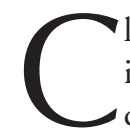

linical evaluation of accommodative and vergence system is an essential part of the study of visual function. The diagnosis of general binocular disorders is performed by means of analysis of accommodative and binocular tests. Some of these tests can be cataloged specifically as accommodative or binocular, basically being assessed in open-loop conditions for the vergence system. This is the case for the cover test, monocular accommodative amplitude, or monocular accommodative facility. However, the remaining tests offer results that are notably influenced by the interactions between accommodation and vergence. As an example, we have the monocular estimate method of dynamic retinoscopy (MEM method), fusional vergences, or relative accommodation.

Special attention is given to fusional vergences and relative accommodations. They evaluate the amount of vergence and accommodation that varies while the stimulus that generates the response in the other system remains constant. Any alteration in the accommodative or vergence system could influence the other system and result in abnormal values of these tests.

Traditionally, fusional vergence results have been considered more important than the findings of relative accommodation. Thus, Saladin ${ }^{1}$ suggests that if the accommodative amplitude, the values of accommodative facility, and those of fusional vergences at far and near distance are known, relative accommodations do not offer new information. Due to the interactions between accommodation and vergence, the values of fusional vergences and relative accommodations are so related that one would think that it is not necessary to study them together in a visual analysis. In fact, some authors $^{2-6}$ do not use relative accommodations for diagnosing general binocular disorders, more because of a question of duplicity than for not being a valid test. However, other authors use relative accommodations as a reference in the diagnosis of accommodative and vergence dysfunctions $s^{7-11}$ or as tests associated with the visual function. ${ }^{12}$

In most of the previous cases, positive relative accommodation (PRA) and negative relative accommodation (NRA) are used as complementary diagnostic tests of some disorders. Hokoda ${ }^{7}$ used a low PRA ( $\leq 1.25 \mathrm{D})$ as one of two supplementary signs that needed to be present in accommodative insufficiency. Scheiman et al. ${ }^{8}$ also used PRA for diagnosing accommodative dysfunction and considered that a low value of NRA $(<1.50 \mathrm{D})$ was related to convergence insufficiency.

Porcar and Martínez-Palomera ${ }^{9}$ considered a low NRA $(\leq 1.50$ D) and PRA ( $\leq 1.25 \mathrm{D})$ associated with accommodative infacility, and they also used this low value of PRA for diagnosing accommodative insufficiency. Finally, García et al. ${ }^{10}$ and Lara et al. ${ }^{11}$ used 
anomalous values of relative accommodations for diagnosing accommodative and binocular anomalies: a low value of PRA $(\leq 1.25$ D) for accommodative insufficiency and convergence excess and a low value of NRA ( $\leq 1.50 \mathrm{D})$ for accommodative excess and convergence insufficiency.

All reports mentioned use abnormally low values of relative accommodations as diagnostic signs of certain dysfunctions, a situation that is justified by the proper etiology of these anomalies. In this sense, a low value of PRA indicates that the patient does not accept the introduction of negative lenses, which could be due to two situations. The first would be that the subject is not able to increase his/her accommodation by the same value as the additional negative lenses, a situation that may be related to an accommodative dysfunction as accommodative insufficiency. The second situation implies that the patient presents an inadequate negative fusional vergence to counter the accommodative vergence generated by the increase in accommodation due to the inserted negative lenses, a situation that would occur in convergence excess.

A low value NRA indicates that the subject does not accept the binocular interposition of positive lenses. In the same manner, this result can be related to an accommodative or vergence problem. If the patient does not accept plus lenses because he is not able to relax the accommodation, it probably indicates accommodative excess. On the other hand, when the subject has an inadequate positive fusional vergence he will not be able to counteract the diminution of accommodative vergence due to the relaxation of the accommodation generated by plus lenses. This would be an example of a patient with convergence insufficiency.

Although high values of PRA and NRA have been obtained in some reports, ${ }^{13}$ in no study cited above are high values of relative accommodations considered as a sign for diagnosing general binocular disorders. The only clear relationships seem to be between high PRA and convergence insufficiency and between a high value of NRA and under- uncorrected hyperopia, ${ }^{14}$ more because of a question of a description of the pathophysiology of these alterations than of a diagnostic sign of them. Concerning the high values of NRA and the under- uncorrected hyperopia, their relation is obvious due to the etiology of this ametropia.

In regard to high values of PRA and convergence insufficiency, it is known that a robust adaptation of accommodation exists in patients with this binocular anomaly. ${ }^{15}$ This, together with their developed negative fusional vergence, causes the patients to easily accept the binocular interposition of minus lenses, resulting in a possible high value of PRA. ${ }^{14}$

Despite the previous considerations, other relationships between the values of relative accommodation and general binocular disorders have not been described. Therefore, the aim of this study was to examine the results of relative accommodations in patients with nonstrabismic binocular dysfunctions to determine the possible relations between their values with each disorder and to investigate how they could be used in diagnosis.

\section{METHODS}

From symptomatic patients presenting consecutively to an optometric clinic, we examined 328 subjects between the ages of 13 and 35 years. The upper limit of 35 years was to avoid patients with accommodative problems that were related to age. All subjects had normal ocular and systemic health, and all of them had at least $20 / 20$ visual acuity with their best correction. None of the subjects wore contact lenses, and subjects with strabismus were also rejected. All subjects gave informed consent after an explanation the nature of the tests to be performed, and subjects authorized the authors to apply the results obtained in this research.

All patients underwent a complete visual examination including the following procedures:

- A case history, reflecting the full range of symptoms presented by the patient.

- Ocular health examination with direct ophthalmoscopy and biomicroscopy.

- Assessment of refractive error. Static retinoscopy procedure was done while the subject was instructed to watch the 20/400 letter E on the distant chart at $6 \mathrm{~m}$. The subjective examination was performed by means of a monocular fogging method with crosscylinder, followed by binocular balancing to a standard endpoint of maximum plus for best visual acuity. This result was called the subjective refractive examination.

- Accommodative and binocular vision testing. With the results of the subjective refractive examination in place (maximum plus for best visual acuity), we conducted an evaluation of accommodative and binocular vision including different tests ${ }^{16}$ : assessment of direction and magnitude of horizontal and vertical phoria with cover test and prism bar at $6 \mathrm{~m}$ and $40 \mathrm{~cm}, \mathrm{AC} / \mathrm{A}$ ratio measured with both calculated and gradient methods, MEM dynamic retinoscopy assessed at $40 \mathrm{~cm}$ by means of a trial frame and trial lenses, positive and negative relative accommodation, monocular and binocular accommodative facility with $\pm 2.00 \mathrm{D}$ flip lenses using a card with acuity suppression, monocular accommodative amplitude by the push-up method, positive and negative fusional vergence (smooth and step vergence with Von Graefe and prism bar method, respectively), nearpoint of convergence, and stereopsis measurement with Wirt circles (Titmus stereotest).

Tests were performed by one examiner who was limited to the procedures. Another author analyzed the data from the patients. Thus, examiner bias for particular test results was avoided. Results of each test were compared with the norms established by Scheiman and Wick ${ }^{16}$ and then grouped according to their deviation from the normal values. Accommodative and binocular anomalies were identified following the criteria of these authors, ${ }^{16}$ taking into account the number of signs used by Lara et al., ${ }^{11}$ which are the most restrictive criteria of those proposed by previous authors. Thus, we used a high number of signs in the diagnosis of these anomalies to use data of those patients who clearly presented some type of dysfunction. Table 1 shows the criteria used in this study for diagnosing accommodative and binocular disorders. From all patients studied, we only recorded for this study the data of those anomalies that were present in more than five subjects to avoid an excessively small sample. With the criteria established, we classified 69 patients ( 40 females and 29 males) with an age range of 13 to 35 years and a mean $( \pm S D)$ age of $20.8 \pm 4.7$. The anomalies were classified as follows: 13 subjects with accommodative insufficiency, 18 patients with accommodative excess, 13 subjects with convergence excess, 6 patients with convergence insufficiency, 10 subjects with convergence excess combined with 
TABLE 1.

Diagnosis criteria for accommodative and binocular disorders

\section{ACCOMMODATIVE INSUFFICIENCY (AI)}

Symptoms. Blurred near vision, discomfort and strain associated with near tasks, fatigue associated with near point tasks, difficulty with attention and concentration when reading.

Signs. Need to present signs 1 and 2, and two of complementary signs (3-5).

1. Reduced amplitude of accomodation. Push-up accommodative amplitude at least $2 \mathrm{D}$ below Hofstetter's calculation for minimum amplitude: $15-0.25 \times$ age.

2. Fails monocular accommodative facility with $-2.00 \mathrm{D}, \leq 6 \mathrm{cpm}$.

3. Fails binocular accommodative facility with $-2.00 \mathrm{D}, \leq 3 \mathrm{cpm}$.

4. High MEM finding, $>+0.75$ D.

5. Low PRA, $\leq 1.25 \mathrm{D}$.

\section{ACCOMMODATIVE EXCESS (AE)}

Symptoms. Blurred distance vision worse after reading or other close work and often worse toward the end of the day, headaches and eyestrain after short periods of reading, difficulty focusing from far to near, sensitivity to light.

Signs. Need to present signs $1-3$ and two of complementary signs (4-6).

1. Variable visual acuity findings.

2. Variable static retinoscopy and subjective refraction.

3. Difficulty clearing $+2.00 \mathrm{D}$ with monocular accommodative facility, $\leq 6 \mathrm{cpm}$.

4. Difficulty clearing $+2.00 \mathrm{D}$ with binocular accommodative facility, $\leq 3 \mathrm{cpm}$.

5. Low MEM finding, $\leq+0.25 \mathrm{D}$.

6. Reduced Negative Relative Accommodation (NRA), $\leq 1.50$ D.

\section{CONVERGENCE EXCESS (CE)}

Symptoms. Associated with reading or other near tasks and generally worse at end of day. The most common includes asthenopia and headaches, intermittent blur.

Signs. Need to present signs 1-2, and two of complementary signs (3-6).

1. Significant esophoria at near, $>2 \Delta$.

2. Reduced negative fusional vergence at near, $\leq 8 / 16 / 7$ for blur, diplopia and recovery (at least one of three).

3. High calculated AC/A ratio, $>7 / 1$.

4. Fails binocular accommodative facility with $-2.00 \mathrm{D}, \leq 3 \mathrm{cpm}$.

5. High MEM, $>+0.75$ D.

6. Low PRA, $\leq 1.25$ D.

\section{CONVERGENCE INSUFFICIENCY (CI)}

Symptoms. Associated with reading or other near tasks, asthenopia, headaches, intermittent blur.

Signs. Need to present signs: $1-3$, and two of complementary signs (4-7).

1. Moderate to high exophoria at near, $>6 \Delta$.

2. Reduced positive fusional vergence at near, $\leq 11 / 14 / 3$ for blur, diplopia and recovery (at least one of three).

3. Receded near point of convergence, $>10 \mathrm{~cm}$ for loss of fusion or $>17.5 \mathrm{~cm}$ for recovery.

4. Low calculated $\mathrm{AC} / \mathrm{A}$ ratio, $<3 / 1$.

5. Fails binocular accommodative facility testing with $+2.00 \mathrm{D}, \leq 3 \mathrm{cpm}$.

6. Low MEM, $<+0.25 \mathrm{D}$.

7. Low NRA, $\leq 1.50 \mathrm{D}$.

accommodative excess, and 9 patients with convergence insufficiency combined with accommodative excess.

The diagnosis of combined accommodative and binocular disorders was done by joining the signs according to Table 1 . In the case of combined convergence excess with accommodative excess, some signs are opposite for both disorders; we classified these patients when they had the signs that needed to be present for both anomalies and at least one of the complementary signs of convergence excess. In regard to combined convergence insufficiency with accommodative excess, most of the complementary signs in both cases are the same; we classified them when the patients with convergence insufficiency also had the signs needed to be present in the accommodative excess.

Positive and negative relative accommodation were assessed using a visual acuity card situated at $40 \mathrm{~cm}$ and with the maximum plus for best visual acuity correction placed in the phoropter.
While the patient fixated the horizontal line of 20/20 letters at 40 $\mathrm{cm}$, the examiner added spherical lenses binocularly. Negative relative accommodation was measured first, adding plus lenses binocularly in $0.25 \mathrm{D}$ steps at the rate of one step every $2 s^{1}$ until the subject reported the first sustained blur. The net amount of plus added was recorded as plus to blur or negative relative accommodation. Then, the amount of plus was reduced or minus was increased binocularly in $0.25 \mathrm{D}$ steps per $2 \mathrm{~s}$ over the refraction placed in the phoropter until the first sustained blur was again reported. PRA was recorded as the amount of minus lenses added over the subjective refractive examination.

To diagnose dysfunctions and analyze the results, we considered the normal values proposed by Scheiman and Wick. ${ }^{16}$ With these norms, PRA has a mean $( \pm S D)$ value of $2.37 \pm 1.00$ so that a low result is considered as being $\leq 1.25 \mathrm{D}$, a high value as $\geq 3.50 \mathrm{D}$, and normal as between these values. In regard to the NRA, the 
mean value is established as $2.00 \pm 0.50 \mathrm{D}$, so that a low value is $\leq 1.50 \mathrm{D}$, a high value is $\geq 2.50 \mathrm{D}$, and normal values are situated between both extremes.

\section{RESULTS}

Of the 69 patients in the sample, 31 had accommodative dysfunctions (13 with accommodative insufficiency and 18 with accommodative excess), 19 had binocular anomalies (13 with convergence excess and six with convergence insufficiency), and 19 had combined accommodative and binocular disorders (10 with convergence excess combined with accommodative excess and nine with convergence insufficiency combined with accommodative excess). In total, there were six different groups of anomalies from which PRA and NRA values were selected for analysis. There were no significant statistical differences between these groups of patients according to age $(p>0.05)$, therefore the age of patients did not affect the results.

\section{Negative Relative Accommodation}

Table 2 shows the descriptive statistics of NRA for each group of dysfunctions, and Fig. 1 represents the mean value of NRA with 1 SD error bars for each dysfunction; the two lines in Fig. 1 indicate the limits of standard deviation for the normal population. It can be established that accommodative excess (AE) is related to relatively low values of NRA. Convergence insufficiency (CI) and convergence insufficiency combined with accommodative excess $(\mathrm{CI}+\mathrm{AE})$ are associated with normal values. Accommodative insufficiency (AI) and convergence excess (CE) are associated with high values of NRA, and the dysfunction of convergence excess combined with accommodative excess $(\mathrm{CE}+\mathrm{AE})$ is related to a normal-high value of NRA.

Having investigated the normality of the six samples (ShapiroWilk test, $\mathrm{p}>0.05$ for all groups) and the equality of variance between them (Levene test, $\mathrm{p}>0.05$ ), we performed an analysis of variance, which showed that significant statistical differences existed between the mean NRA values $(F=20.289$, $\mathrm{p}<0.01)$. Post hoc analysis using the Scheffé test determined the differences between the groups (Table 3).

As can be observed, there are statistical differences between the AE group and the rest of the dysfunctions, except for the CI group. Because the AE group is related to a low value of NRA, ${ }^{10,11}$ it can be assured that a high value of NRA is not associated with the accommodative excess. In this sense, it cannot be affirmed that a low value of NRA distinguishes between the group with $\mathrm{AE}$ and the others because there are no differences between this dysfunction and the group with CI.

There are no significant differences between the two groups of disorders that were associated with a high NRA, AI and CE. Moreover, there were no significant differences between the disorders with normal values ${ }^{16}$ of NRA: $\mathrm{CI}, \mathrm{CE}+\mathrm{AE}$, and $\mathrm{CI}+\mathrm{AE}$.

According to the disorders with high NRA (AI and CE), there were differences between these anomalies and the disorders of $\mathrm{AE}$ and CI. Despite these statistical differences, it cannot be assured that a high value of NRA is clearly related to some type of dysfunction. As an example, a high NRA could be associated with a disorder such as AI or CE. However, because there are no differences with the anomaly of $\mathrm{CE}+\mathrm{AE}$, or between $\mathrm{AI}$ and $\mathrm{CI}+\mathrm{AE}$, it is not possible to assure that this high value of NRA is only related to accommodative insufficiency or convergence excess.

\section{Positive Relative Accommodation}

Table 4 shows some descriptive statistics for the PRA data of each group of anomalies. Fig. 2 shows the mean value and 1 SD of PRA for each dysfunction, together with two lines that indicate the limits of the standard deviation for the normal population. ${ }^{16}$ As can be observed, mean values of PRA for convergence excess and convergence insufficiency can be classified as normal. PRA in accommodative insufficiency is related to a low value, whereas the other three groups of dysfunctions are associated with high values of PRA.

To determine whether there were differences between values of PRA, we performed an analysis of variance, having verified that the six groups had a normal distribution (Shapiro-Wilk test, $\mathrm{p}>0.05$ for all cases) and proved the equality of variances between them (Levene test, $\mathrm{p}>0.05$ ). Analysis of variance showed that there were significant statistical differences between the six groups of dysfunctions according to the mean value of PRA ( $\mathrm{F}=14.99, \mathrm{p}<$ 0.01). Table 5 shows post hoc analysis using the Scheffe test, assessed for determining significant differences between groups.

Analyzing the differences between groups, it is possible to establish certain considerations. First, significant differences exist between PRA mean values of AI and those groups where AE appears. Because accommodative insufficiency is related to low PRA, ${ }^{7-9}$ it can be established that a low value of PRA will not be related to the dysfunctions where accommodative excess is present.

On the other hand, there are no significant differences between

TABLE 2.

Summary of results for negative relative accommodation in each diagnostic group

\begin{tabular}{|c|c|c|c|c|c|}
\hline Dysfunction & $\begin{array}{c}\text { No. of } \\
\text { Subjects }\end{array}$ & Mean & SD & Minimum & Maximum \\
\hline $\mathrm{Al}^{a}$ & 13 & 2.75 & 0.38 & 2.00 & 3.25 \\
\hline $\mathrm{AE}$ & 18 & 1.64 & 0.47 & 1.00 & 2.50 \\
\hline CE & 13 & 2.87 & 0.26 & 2.50 & 3.25 \\
\hline $\mathrm{Cl}$ & 6 & 1.75 & 0.22 & 1.50 & 2.00 \\
\hline $\mathrm{CE}+\mathrm{AE}$ & 10 & 2.45 & 0.40 & 2.00 & 3.00 \\
\hline $\mathrm{Cl}+\mathrm{AE}$ & 9 & 2.22 & 0.51 & 1.50 & 3.00 \\
\hline
\end{tabular}

\footnotetext{
${ }^{a} \mathrm{Al}$, accommodative insufficiency; $\mathrm{AE}$, accommodative excess; $\mathrm{CE}$, convergence excess; $\mathrm{Cl}$, convergence insufficiency.
} 


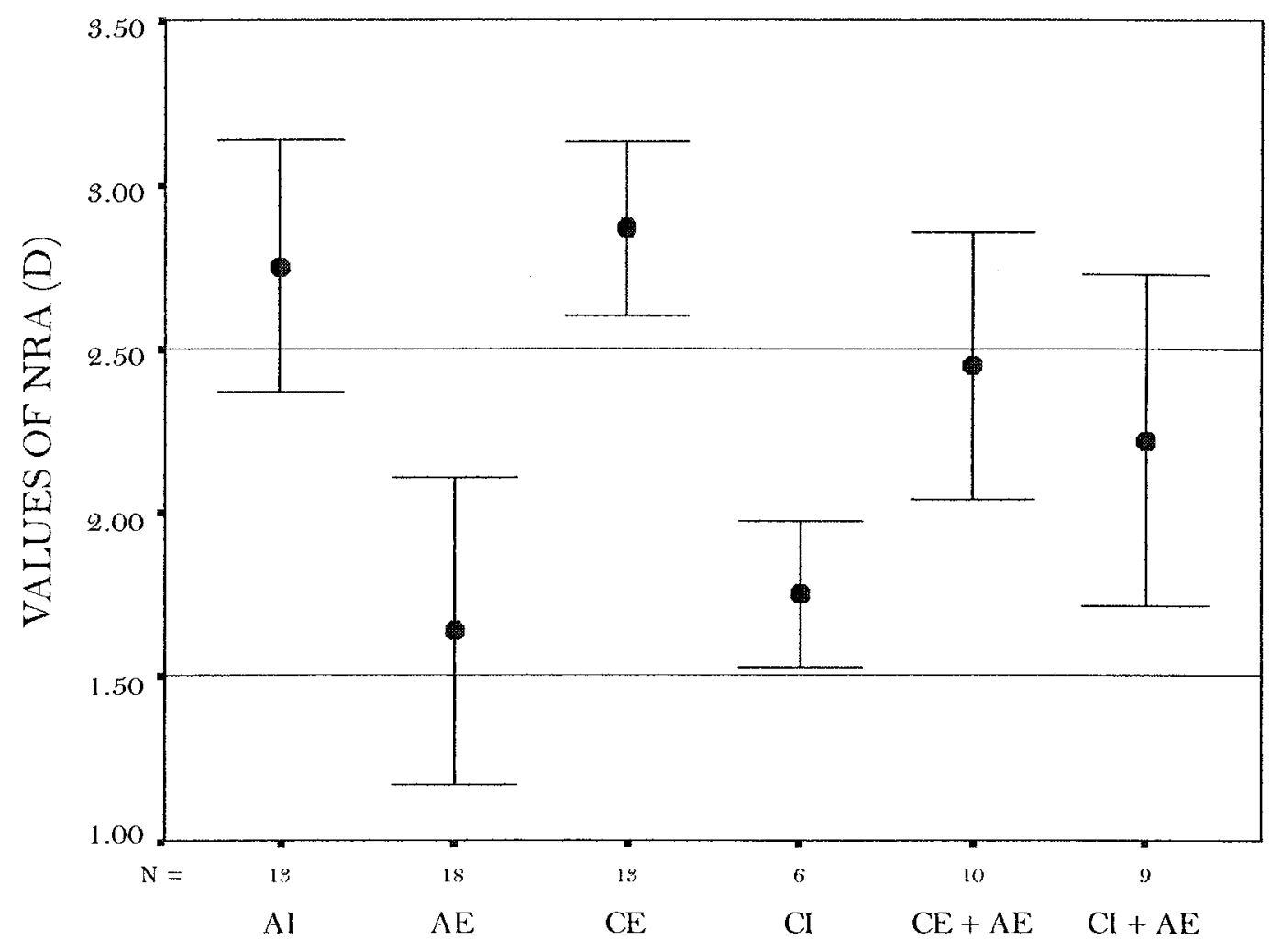

TYPE OF DYSFUNCTION

\section{FIGURE 1.}

Mean value of negative relative accommodation (NRA) $\pm 1 \mathrm{SD}$ for each group of dysfunction. $\mathrm{Al}$, accommodative insufficiency; $\mathrm{AE}$, accommodative excess; $\mathrm{CE}$, convergence excess; $\mathrm{Cl}$, convergence insufficiency.

\section{TABLE 3.}

Mean differences for negative relative accommodation by dysfunctions using Scheffe's method

\begin{tabular}{|c|c|c|}
\hline \multirow{2}{*}{$\begin{array}{c}\text { Contrast of } \\
\text { Means }\end{array}$} & \multirow{2}{*}{$\begin{array}{c}\text { Mean } \\
\text { Differences }\end{array}$} & $\begin{array}{l}95 \% \text { Confidence Interval } \\
\text { of the Difference }\end{array}$ \\
\hline & & $r$ Limit \\
\hline
\end{tabular}

\begin{tabular}{|c|c|c|c|}
\hline Al vs. $\mathrm{AE}^{a}$ & $1.111^{b}$ & 0.610 & 1.613 \\
\hline Al vs. CE & -0.115 & -0.656 & 0.425 \\
\hline Al vs. $\mathrm{Cl}$ & $1.000^{b}$ & 0.320 & 1.680 \\
\hline $\mathrm{Al}$ vs. $\mathrm{CE}+\mathrm{AE}$ & 0.300 & -0.280 & 0.880 \\
\hline $\mathrm{Al}$ vs. $\mathrm{Cl}+\mathrm{AE}$ & 0.528 & -0.007 & 1.125 \\
\hline AE vs. CE & $-1.227^{b}$ & -1.728 & -0.725 \\
\hline AE vs. $\mathrm{Cl}$ & -0.111 & -0.761 & 0.539 \\
\hline$A E$ vs. $C E+A E$ & $-0.811^{b}$ & -1.355 & -0.268 \\
\hline AE vs. $\mathrm{Cl}+\mathrm{AE}$ & $-0.583^{b}$ & -1.146 & -0.002 \\
\hline CE vs. Cl & $1.115^{b}$ & 0.435 & 1.796 \\
\hline CE vs. $\mathrm{CE}+\mathrm{AE}$ & 0.415 & -0.164 & 0.995 \\
\hline CE vs. $\mathrm{Cl}+\mathrm{AE}$ & $0.643^{b}$ & 0.005 & 1.241 \\
\hline $\mathrm{Cl}$ vs. $\mathrm{CE}+\mathrm{AE}$ & -0.700 & -1.412 & 0.001 \\
\hline $\mathrm{Cl}$ vs. $\mathrm{Cl}+\mathrm{AE}$ & -0.472 & -1.199 & 0.254 \\
\hline $\mathrm{CE}+\mathrm{AE}$ vs. $\mathrm{Cl}+\mathrm{AE}$ & 0.228 & -0.405 & 0.861 \\
\hline
\end{tabular}

\footnotetext{
${ }^{a} \mathrm{Al}$, accommodative insufficiency; $\mathrm{AE}$, accommodative excess; $\mathrm{CE}$, convergence excess; $\mathrm{Cl}$, convergence insufficiency.

${ }^{b} \mathrm{p}<0.05$.
}

$\mathrm{AI}$ and $\mathrm{CE}$ and $\mathrm{CI}$ with regard to mean value of PRA. As was observed in Fig. 2, these two disorders (CE and CI) can be associated with a value of PRA between normal limits, thus normal results or low values of PRA do not distinguish statistically between these three anomalies.

Between the groups of disorders that were associated with a high value of PRA, significant statistical differences do not exist. However, these differences appear when the groups of $\mathrm{AE}$ and $\mathrm{CI}+\mathrm{AE}$ are compared with disorders of $\mathrm{CE}$ and $\mathrm{CI}$. There are no significant differences between these dysfunctions (CE and $\mathrm{CI}$ ) and the group with $\mathrm{CE}+\mathrm{AE}$. These findings suggest that, in general, the high values of PRA can distinguish between dysfunctions, particularly between those anomalies related to accommodative excess and the remainder.

As it has been shown up to this point, the clearest results connect the relative accommodation with the dysfunctions in which accommodative excess appears, so that a low value of PRA is not associated with accommodative excess, whereas a high value is related to this disorder, and a high value of NRA is not associated with this accommodative anomaly. To evaluate with greatest precision the importance of the relative accommodation in the disorders associated with accommodative excess, we decided to study the specificity and sensitivity of all complementary signs that are used in the diagnosis of these anomalies together with the sign of PRA. 
TABLE 4.

Summary of results for positive relative accommodation in each diagnostic group

\begin{tabular}{lccccc}
\hline Dysfunction & $\begin{array}{c}\text { No. of } \\
\text { Subjects }\end{array}$ & Mean & SD & Minimum & Maximum \\
\hline $\mathrm{Al}^{a}$ & 13 & 1.48 & 0.68 & 0.50 & 3.00 \\
$\mathrm{AE}$ & 18 & 4.43 & 1.71 & 2.00 & 8.75 \\
$\mathrm{CE}$ & 13 & 2.44 & 1.12 & 1.00 & 4.50 \\
$\mathrm{Cl}$ & 6 & 2.42 & 0.74 & 1.75 & 3.75 \\
$\mathrm{CE}+\mathrm{AE}$ & 10 & 3.40 & 1.02 & 3.25 & 5.00 \\
$\mathrm{Cl}+\mathrm{AE}$ & 9 & 5.25 & 1.30 & 7.25 \\
\hline
\end{tabular}

${ }^{a} \mathrm{Al}$, accommodative insufficiency; $\mathrm{AE}$, accommodative excess; $\mathrm{CE}$, convergence excess; $\mathrm{Cl}$, convergence insufficiency.

\section{Specificity and Sensitivity of Disorders Associated with Accommodative Excess}

Specificity can be understood as the percentage of subjects who pass a particular test and are classified, in this case, without relation to the accommodative excess. It can be calculated by means of the ratio between the number of subjects without dysfunctions who pass the test analyzed and the number of patients without dysfunctions studied. The sensitivity can be calculated as the percentage of subjects who fail the particular test and are classified with dysfunctions related to accommodative excess. It can be calculated by means of the ratio between the number of subjects with accommo- dative excess who fail the test analyzed and the total number of patients studied who have accommodative excess.

The criteria used for diagnosing the anomalies studied are shown in Table 1, where it is specified that in accommodative excess the complementary signs were MEM $<+0.25 \mathrm{D}$, NRA $\leq 1.50 \mathrm{D}$, and difficulty clearing with $+2.00 \mathrm{D}$ in binocular accommodative facility (BAF) $\leq 3 \mathrm{cpm}$. When convergence insufficiency is associated with accommodative excess, the complementary signs are those listed before, together with a calculated ratio of $\mathrm{AC} / \mathrm{A}<3 / 1$. In convergence excess combined with accommodative excess, certain flexibility in the use of the complementary signs is needed because some of them are contradictory in both dysfunc-

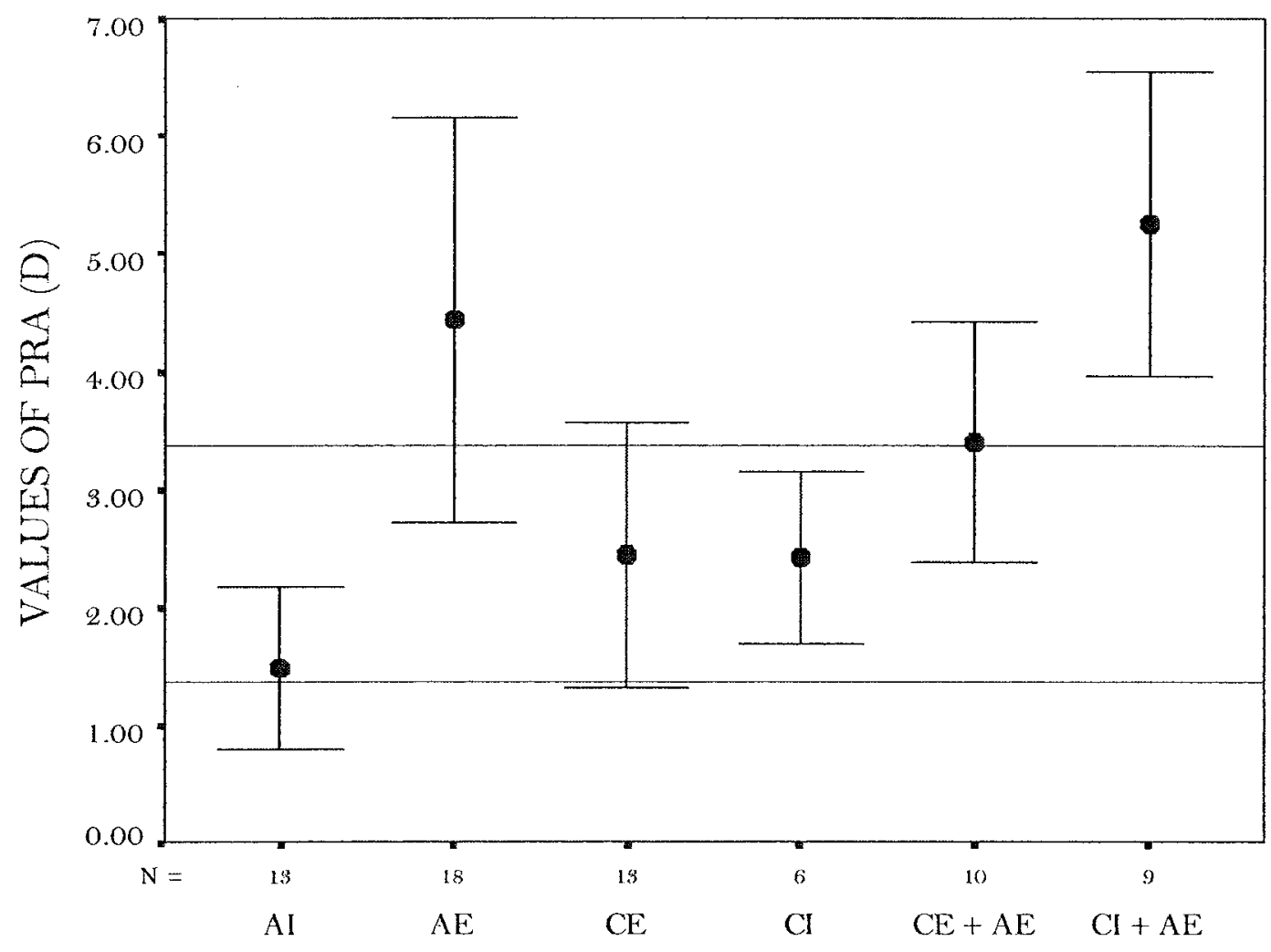

TYPE OF DYSFUNCTION

FIGURE 2.

Mean value of positive relative accommodation (PRA) $\pm 1 \mathrm{SD}$ for each group of dysfunction. $\mathrm{Al}$, accommodative insufficiency; $\mathrm{AE}$, accommodative excess; $\mathrm{CE}$, convergence excess; $\mathrm{Cl}$, convergence insufficiency. 
TABLE 5.

Mean differences for positive relative accommodation by dysfunctions using Scheffe's method

\begin{tabular}{|c|c|c|c|}
\hline \multirow[t]{2}{*}{ Contrast of Means } & \multirow{2}{*}{$\begin{array}{c}\text { Mean } \\
\text { Differences }\end{array}$} & \multicolumn{2}{|c|}{$\begin{array}{l}\text { 95\% Confidence } \\
\text { Interval of the } \\
\text { Difference }\end{array}$} \\
\hline & & $\begin{array}{l}\text { Lower } \\
\text { Limit }\end{array}$ & $\begin{array}{l}\text { Higher } \\
\text { Limit }\end{array}$ \\
\hline Al vs. $\mathrm{AE}^{a}$ & $-2.950^{b}$ & -4.496 & -1.404 \\
\hline Al vs. CE & -0.962 & -2.628 & 0.704 \\
\hline $\mathrm{Al}$ vs. $\mathrm{Cl}$ & -0.936 & -3.032 & 1.160 \\
\hline $\mathrm{Al}$ vs. $\mathrm{CE}+\mathrm{AE}$ & $-1.919^{b}$ & -3.706 & -0.133 \\
\hline $\mathrm{Al}$ vs. $\mathrm{Cl}+\mathrm{AE}$ & $-3.769^{b}$ & -5.611 & -1.928 \\
\hline AE vs. CE & $1.988^{b}$ & 0.442 & 3.534 \\
\hline AE vs. $\mathrm{Cl}$ & $2.014^{b}$ & 0.001 & 4.016 \\
\hline $\mathrm{AE}$ vs. $\mathrm{CE}+\mathrm{AE}$ & 1.031 & -0.645 & 2.706 \\
\hline $\mathrm{AE}$ vs. $\mathrm{Cl}+\mathrm{AE}$ & -0.819 & -2.553 & 0.915 \\
\hline CE vs. $\mathrm{Cl}$ & 0.003 & -2.071 & 2.122 \\
\hline CE vs. $\mathrm{CE}+\mathrm{AE}$ & -0.958 & -2.744 & 0.829 \\
\hline $\mathrm{CE}$ vs. $\mathrm{Cl}+\mathrm{AE}$ & $-2.808^{b}$ & -4.650 & -0.966 \\
\hline $\mathrm{Cl}$ vs. $\mathrm{CE}+\mathrm{AE}$ & -0.983 & -3.177 & 1.210 \\
\hline $\mathrm{Cl}$ vs. $\mathrm{Cl}+\mathrm{AE}$ & $-2.833^{b}$ & -5.072 & -0.595 \\
\hline $\mathrm{CE}+\mathrm{AE}$ vs. $\mathrm{Cl}+\mathrm{AE}$ & -1.850 & -3.802 & 0.102 \\
\hline
\end{tabular}

${ }^{a} \mathrm{Al}$, accommodative insufficiency; $\mathrm{AE}$, accommodative excess; $\mathrm{CE}$, convergence excess; $\mathrm{Cl}$, convergence insufficiency.

${ }^{b} \mathrm{p}<0.05$.

tions. In $\mathrm{CE}$, one finds a value of $\mathrm{AC} / \mathrm{A}$ more than $7 / 1, \mathrm{BAF} \leq 3$ cpm failing with minus lenses, MEM $>+0.75 \mathrm{D}$, and PRA $\leq 1.25 \mathrm{D}$. To these signs can be added a high value of PRA related to accommodative excess, as has been established in this paper.

Taking into account these criteria, to study the specificity and sensitivity, it is necessary to know the cutoff for each sign to establish when a patient passes or fails the test. Table 6 shows the cutoff values used, following the limits proposed by the standard deviation of the normal values suggested by Scheiman and Wick. ${ }^{16}$
To calculate the specificity of the diagnostic signs in accommodative excess, a sample of patients without general binocular dysfunctions is needed. To perform this analysis, we randomly selected from our sample of patients the data of 20 normal subjects who had this condition. The signs analyzed had the following specificity: $\mathrm{BAF}=0.9(18 / 20) ; \mathrm{MEM}=0.9(18 / 20) ; \mathrm{NRA}=1.0$ $(20 / 20)$, and PRA $=0.9(18 / 20)$. In all cases, high values were reached, a finding that indicates that if the established cutoffs are used, there is a high probability that a patient who passes each test could be classified as a subject without accommodative excess. This result is logical, but has minimal clinical interest.

For the rest of the dysfunctions associated with accommodative excess, the specificity had similar values because the population was the same in all cases and the considerations about the results were not different from those mentioned.

For the assessment of sensitivity, we took into account data from 18 patients with $\mathrm{AE}, 9$ subjects with $\mathrm{CI}+\mathrm{AE}$, and the 10 patients who presented $\mathrm{CE}+\mathrm{AE}$. The sensitivity results for each complementary sign presented in these disorders are shown in Table 7.

For accommodative excess, the most sensitive signs were BAF $\leq 3 \mathrm{cpm}$ with difficulty with plus lenses (0.72) and PRA $\geq 3.50 \mathrm{D}$ (0.72). These results indicate that more than $70 \%$ of the patients with accommodative excess will have high values of PRA or/and will fail the binocular accommodative facility test. The probability of encountering a high value of PRA in these patients was higher than a finding of a low MEM value or a result of NRA $<1.50 \mathrm{D}$.

In patients with $\mathrm{CI}+\mathrm{AE}$, the most sensitive sign was high $\mathrm{PRA}$ (0.89), which was higher than failing BAF (0.78) or a low calculated AC/A (0.78). Again, there was a high probability that a patient with this accommodative combined binocular dysfunction had a high value of PRA.

Finally, in patients with $\mathrm{CE}+\mathrm{AE}$, we studied the sensitivity of all complementary signs corresponding to $\mathrm{CE}$ and to $\mathrm{AE}$. As can be observed in Table 7 , the most sensitive signs were the presence of a high-calculated AC/A (0.90), followed by a high value of PRA (0.70). Again, in these patients, there was a high probability of encountering high values of PRA.

\section{TABLE 6.}

Cutoff used to calculate specificity and sensitivity

\begin{tabular}{|c|c|c|}
\hline Signs & Fail the Test & Pass the Test \\
\hline \multicolumn{3}{|l|}{$\mathrm{AE}^{\mathrm{a}}$} \\
\hline BAF & $\leq 3 \mathrm{cpm}$ (fail with +2.00 D) & $>3 \mathrm{cpm}$ \\
\hline MEM & $<+0.25 \mathrm{D}$ & $\geq+0.25 \mathrm{D}$ \\
\hline NRA & $\leq 1.50 \mathrm{D}$ & $>1.50 \mathrm{D}$ \\
\hline PRA & $\geq 3.50 \mathrm{D}$ & $<3.50 \mathrm{D}$ \\
\hline \multicolumn{3}{|c|}{$\mathrm{Cl}+\mathrm{AE}$} \\
\hline \multicolumn{3}{|c|}{ All signs of AE together with: } \\
\hline \multicolumn{3}{|c|}{$\mathrm{CE}+\mathrm{AE}$} \\
\hline \multicolumn{3}{|c|}{ All signs of AE together with: } \\
\hline BAF & $\leq 3 \mathrm{cpm}$ (fail with $-2.00 \mathrm{D})$ & $>3 \mathrm{cpm}$ \\
\hline MEM & $>+0.75 \mathrm{D}$ & $\leq+0.75 \mathrm{D}$ \\
\hline PRA & $\leq 1.25 \mathrm{D}$ & $>1.25 \mathrm{D}$ \\
\hline AC/A calculated & $>7 / 1$ & $\leq 7 / 1$ \\
\hline
\end{tabular}

$\mathrm{AE}$, accommodative excess; $\mathrm{BAF}$, binocular accommodative facility; MEM, monocular estimate method; $N$ RA, negative relative accommodation; PRA, positive relative accommodation; $\mathrm{Cl}$, convergence insufficiency; $\mathrm{CE}$, convergence excess. 
TABLE 7.

Sensitivity of the complementary diagnostic tests for accommodative excess, convergence insufficiency + accommodative excess, and convergence excess + accommodative excess

\begin{tabular}{lr}
\hline \multicolumn{1}{c}{ Signs } & Sensitivity \\
\hline $\mathrm{AE}(\mathrm{N}=18)^{a}$ & \\
$\mathrm{BAF} \leq 3 \mathrm{cpm}(+)$ & $0.72(13 / 18)$ \\
$\mathrm{MEM}<+0.25 \mathrm{D}$ & $0.67(12 / 18)$ \\
$\mathrm{NRA} \leq 1.50 \mathrm{D}$ & $0.61(11 / 18)$ \\
$\mathrm{PRA} \geq 3.50 \mathrm{D}$ & $0.72(13 / 18)$ \\
$\mathrm{CI}+\mathrm{AE}(\mathrm{N}=9)$ & \\
$\mathrm{BAF} \leq 3 \mathrm{cpm}(+)$ & $0.78(7 / 9)$ \\
$\mathrm{MEM}<+0.25 \mathrm{D}$ & $0.33(3 / 9)$ \\
$\mathrm{NRA} \leq 1.50 \mathrm{D}$ & $0.22(2 / 9)$ \\
$\mathrm{PRA} \geq 3.50 \mathrm{D}$ & $0.89(8 / 9)$ \\
$\mathrm{AC} / \mathrm{A}$ calculated $<3 / 1$ & $0.78(7 / 9)$ \\
$\mathrm{CE}+\mathrm{AE}(\mathrm{N}=10)$ & \\
$\mathrm{BAF} \leq 3 \mathrm{cpm}(+)$ & $0.20(2 / 10)$ \\
$\mathrm{MEM}<+0.25 \mathrm{D}$ & $0.40(4 / 10)$ \\
$\mathrm{NRA} \leq 1.50 \mathrm{D}$ & $0(0 / 10)$ \\
$\mathrm{PRA} \geq 3.50 \mathrm{D}$ & $0.70(7 / 10)$ \\
$\mathrm{BAF} \leq 3 \mathrm{cpm}(-)$ & $0.30(3 / 10)$ \\
$\mathrm{MEM}>+0.75$ & $0.10(1 / 10)$ \\
$\mathrm{PRA} \leq 1.25 \mathrm{D}$ & $0(0 / 10)$ \\
$\mathrm{AC} / \mathrm{A}$ calculated $>7 / 1$ & $0.90(9 / 10)$ \\
\hline A AE accommodatve
\end{tabular}

${ }^{a} \mathrm{AE}$, accommodative excess; $\mathrm{BAF}$, binocular accommodative facility; MEM, monocular estimate method; NRA, negative relative accommodation; PRA, positive relative accommodation; $\mathrm{Cl}$, convergence insufficiency; $\mathrm{CE}$, convergence excess.

\section{DISCUSSION}

Values of relative accommodations have been used in several studies in a secondary way for diagnosing nonstrabismic binocular dysfunctions. Traditionally, their importance has been less than other binocular tests, and some authors have not included them when assessing the diagnosis of general binocular anomalies. ${ }^{2-6}$

Depending on the authors, ${ }^{7-11}$ the anomalous values of relative accommodations can be associated with particular dysfunctions. Thus, a low value of NRA may be encountered in convergence insufficiency and with accommodative excess, whereas a reduced PRA is associated with accommodative insufficiency and with convergence excess.

The findings of this study partly confirm these opinions. In fact, in accommodative excess, NRA values are diminished, but this does not occur in convergence insufficiency because they are within the limits established by the standard deviation for a normal population. ${ }^{16}$ Despite this, there are no significant differences between the values of NRA for these two groups. It can only be affirmed that a high value of NRA will not be related to the accommodative excess.

On the other hand, it could be thought that in those patients who show both convergence insufficiency and accommodative excess, NRA values would be necessarily diminished. However, as is shown in Table 2 and in Fig. 1, NRA in these patients can be considered normal and only differs statistically from accommodative excess, which is related to low values of NRA, and convergence excess, which is related to high values of NRA. Moreover, the sensitivity of a low value of NRA in these patients was only $22 \%$ (Table 7), which is lower than other signs such as BAF or a low calculated AC/A.

The high values of NRA can be associated with disorders such as accommodative insufficiency and convergence excess, although statistically one must not rule out other anomalies when there is a high result of NRA. In view of these results, one could think that the NRA results do not clearly distinguish between dysfunctions, so their use should be complementary to other binocular tests when diagnosing general binocular disorders, as is used currently.

In regard to PRA results, we encountered diminished values in accommodative insufficiency, although this did not occur in convergence excess. Because there are no differences between accommodative insufficiency and convergence excess or convergence insufficiency, we can suggest that a low value of PRA does not distinguish between these three dysfunctions.

The high results of PRA are related to anomalies in which accommodative excess appears. In particular, values of PRA in accommodative excess and in the combined dysfunction of convergence insufficiency and accommodative excess showed statistical differences from disorders not associated with accommodative excess. In this case, we can assure that, in general, a high value of PRA can distinguish between the disorders related to accommodative excess and the others.

The values of PRA in combined convergence excess with accommodative excess were also elevated, but not as much as in other dysfunctions in which accommodative excess appears. This is possibly because PRA in convergence excess has normal values that can be increased noticeably in those patients with an associated accommodative excess, although not enough to present significant differences with the disorders of normal PRA (CE and CI).

Some authors ${ }^{14-15}$ suggest that PRA values can be elevated in patients with convergence insufficiency. Our results reveal that in subjects with only $\mathrm{CI}$, the values of PRA are within the normal limits. However, when the $\mathrm{CI}$ is associated with accommodative excess, the PRA reaches high levels. In these patients, accommodative excess is secondary to convergence insufficiency, thus it can be assured that the increase of PRA is directly related with the apparition of accommodative excess.

The sensitivity of a high PRA in disorders associated with AE (Table 7) corroborates the preceding considerations. In patients with $\mathrm{CE}+\mathrm{AE}$, the sensitivity of a value of PRA $\geq 3.50 \mathrm{D}$ is 0.70 , only exceeded by the presence of a high-calculated AC/A (0.90). It is important to point out that in these subjects, the presence of a low MEM finding, which is characteristic of AE, is more sensitive than the finding of a high MEM value, characteristic of CE. This fact corroborates the influence of accommodative excess in certain binocular parameters related with convergence excess.

The sensitivity of high PRA in subjects with AE is 0.72 , the same result as the sign of failing BAF and only slightly higher than the signs of low MEM and diminished NRA. In patients with convergence insufficiency combined with accommodative excess, the most sensitive sign is a high value of PRA (0.89), followed by the difficulty with BAF and the low calculated AC/A (0.78 in both cases) and very remote from the signs of low MEM and low NRA. These results corroborate the importance of high PRA in disorders associated with accommodative excess, thus the finding of a PRA 
value $>3.50 \mathrm{D}$ should be included as a diagnostic sign related to accommodative excess.

\section{CONCLUSIONS}

The use of NRA in the diagnosis of nonstrabismic binocular dysfunctions must be complementary to other binocular tests because an anomalous value cannot be related particularly to any dysfunction. This is corroborated by the absence of significant differences between the high, normal, and low values of NRA.

Concerning positive relative accommodation, it seems clear that there is a relationship between the anomalies associated with accommodative excess and the presence of a high value of positive relative accommodation. The finding of a PRA $>3.50 \mathrm{D}$ in patients with convergence insufficiency combined with accommodative excess is of special interest because it is the most sensitive sign related to this combined dysfunction. Therefore, the results of this study suggest that a high value of PRA should be included as a diagnostic sign in general binocular disorders associated with accommodative excess.

\section{ACKNOWLEDGMENT}

Received August 29, 2001; revision received April 8, 2002.

\section{REFERENCES}

1. Saladin JJ. Phorometry and stereopsis. In: Benjamin WJ, Borish IM, eds. Borish's Clinical Refraction. Philadelphia: WB Saunders, 1998: 724-73.

2. Daum KM. Accommodative dysfunction. Doc Ophthalmol 1983; 55:177-98.

3. Matsuo T, Ohtsuki H. Follow-up results of a combination of accommodation and convergence insufficiency in school-age children and adolescents. Graefes Arch Clin Exp Ophthalmol 1992;230:166-70.

4. Russell GE, Wick B. A prospective study of treatment of accommodative insufficiency. Optom Vis Sci 1993;70:131-5.

5. Dwyer P, Wick B. The influence of refractive correction upon disorders of vergence and accommodation. Optom Vis Sci 1995;72: 224-32.
6. Rouse MW, Hyman L, Hussein M, Solan H, the Convergence Insufficiency and Reading Study (CIRS) Group: frequency of convergence insufficiency in optometry clinic settings. Optom Vis Sci 1998;75: 88-96.

7. Hokoda SC. General binocular dysfunctions in an urban optometry clinic. J Am Optom Assoc 1985;56:560-2.

8. Scheiman M, Gallaway M, Coulter R, Reinstein F, Ciner E, Herzberg C, Parisi M. Prevalence of vision and ocular disease conditions in a clinical pediatric population. J Am Optom Assoc 1996;67:193-202.

9. Porcar E, Martinez-Palomera A. Prevalence of general binocular dysfunctions in a population of university students. Optom Vis Sci 1997; 74:111-3.

10. Garcia A, Cacho P, Lara F, Megias R. The relation between accommodative facility and general binocular dysfunction. Ophthalmic Physiol Opt 2000;20:98-104.

11. Lara F, Cacho P, Garcia A, Megias R. General binocular disorders: prevalence in a clinic population. Ophthalmic Physiol Opt 2001;21: $70-4$.

12. Atchison DA, Schmid KL, Edwards KP, Muller SM, Robotham J. The effect of under and over refractive correction on visual performance and spectacle lens acceptance. Ophthalmic Physiol Opt 2001; 21:255-61.

13. Jackson TW, Goss DA. Variation and correlation of clinical tests of accommodative function in a sample of school-age children. J Am Optom Assoc 1991;62:857-66.

14. Newman JM. Analysis, interpretation and prescription for the ametropias and heterophorias. In: Benjamin WJ, Borish IM, eds. Borish's Clinical Refraction. Philadelphia: WB Saunders, 1998: 776-822.

15. Schor C, Horner D. Adaptive disorders of accommodation and vergence in binocular dysfunction. Ophthalmic Physiol Opt 1989;9: 264-8.

16. Scheiman M, Wick B. Clinical Management of Binocular Vision: Heterophoric, Accommodative and Eye Movement Disorders. Philadelphia: Lippincott, 1994.

Ángel García Muñoz Departamento Interuniversitario de Óptica Apartado 99. Universidad de Alicante 03080 Alicante Spain e-mail:ag.munoz@ua.es 